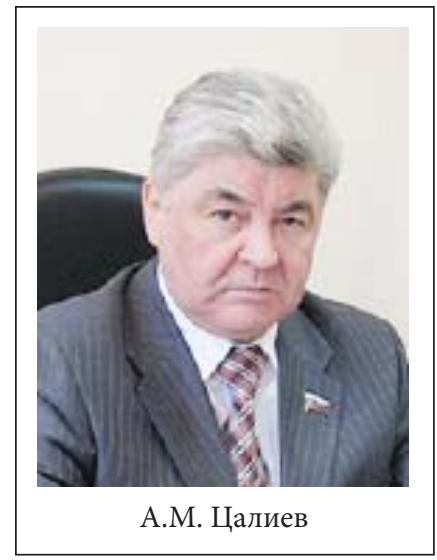

УДК 321(091)

DOI 10.23671/VNC.2018.4.23786

\title{
ВАЖНОЕ СОБЫТИЕ В ИСТОРИИ РЕГИОНАЛЬНОГО КОНСТИТУЦИОНАЛИЗМА (к 100-летию принятия 1-й Конституции Осетии)
}

\author{
А.М. Цалиев"
}

\begin{abstract}
Аннотация. Рассматривается и анализируется принятое 1 рревраля 1918 г. Положение "Об Осетинском национальном совете», его структура и полномочия, задачи органов власти. Приводятся убедительные аргументы, свидетельствующие о том, что указанное Положение стало 1-й Конституцией Осетии, обосновывается взаимосвязь писаного и неписаного права, социальная иенность норм обычного права.

Ключевые слова: V Съезд осетинского народа, Положение "Об Осетинском национальном совете», национальные собрания, 1-я Конституция Осетии, фрункции Конституции, писаное и неписаное право.
\end{abstract}

Народ Осетии, как и любой другой народ, в своем государственно-правовом развитии прошел определенные важные исторические этапы развития. Несомненно, к числу их в советский период относятся создание новых органов публичной власти (высших и местных) и начало формирования нового права писаного (законы и другие нормы, исходящие от органов власти и зафиксированные ими в определенной редакции) в виде Основного закона. К сожалению, во многих случаях это не могло не быть связано с борьбой за государственную власть, установлением той или иной ее формы. В данном случае речь идет о Советской власти, когда в пылу борьбы за или против нее исследователи забывали достойно осветить $и$ отметить знаменательные события в истории своего народа.

Речь идет о состоявшемся 1 (14) февраля 1918 г. в Ардоне V Съезде осетинского народа, когда в сложнейшее время борьбы за государственную власть, гражданской войны участники съезда по докладу Г. Ф. Баракова обсудили общее положение в Терской области, особенно в Осетии. Съезд объявил изменниками порядка и дела национального возрождения Осетии отдельные группы и элементы, допускавшие в последнее время безответственные выступления, идущие вразрез с революционными завоеваниями, и заявил, что он «отвергает всякую мысль о войне с соседними братскими народами и верит, что начатые по инициативе отдельных групп безумные столкновения прекратятся окончательно» [1].

На данном съезде был принят чрезвычайно важный конституционный документ - Положение ${ }^{1}$ (Конституция) «Об Осетинском национальном совете», призванное происходящие в Осетии после революции события направить в русло цивилизованной государственно-правовой жизни в рамках 1-й осетинской Конституции. Хотя сам документ назывался Положением, нет никаких сомнений в том, что речь идет о Конституции, о чем свидетельствует ряд его норм. В частности, в примечании к статье 6 Положения говорится, что
«Национальный совет в силу предоставленных ему п. 6 Конституции прав контроля...».

Согласно статье 15 «депутаты избираются на один год и приносят присягу в верности настоящей Конституции». Пример, достойный подражания и в наше время, ведь присяга - официальное и торжественное обещание (клятва) при поступлении на военную или иную службу, получении определенного статуса, вступлении в должность. Уверен, что такое торжественное вступление в должность не только придает определенный статус тому, кто приносит присягу, но и способствует повышению уровня ответственности за эфффективность его профессиональной деятельности.

В соответствии со статьей 28 Положения «в настоящую Конституцию могут быть внесены поправки, изменения и дополнения Национальным собранием». О том, что речь идет о 1-й Конституции Осетии, свидетельствуют также анализ ее содержания и предусмотренные в ней конституционные функции.

Однако данный исторически важный конституционный документ фрактически остался вне общественного внимания и не получил должной оценки в осетинской исторической и юридической науке. Так, в академическом издании «История Северо-Осетинской АССР» (Орджоникидзе, 1966) ни одного слова не сказано об этом важном документе и 1-м Осетинском съезде. То же самое повторилось в фундаментальной монографии «История Осетии. XX век» (Владикавказ, 2003). Более того, в конце работы, перечисляя знаменательные события, авторы данного раздела не посчитали нужным отметить среди них V Осетинский съезд и принятые на нем решения!

Между тем на данном съезде и в принятой на нем Конституции (Положении) были сформированы первые официальные представительные органы народа Осетии. Так, согласно Конституции, высшая власть на территории Осетии принадлежала Осетинскому национальному собранию, то есть Съезду народа и Oceтинскому национальному совету. Последний являлся: а) законодательным собранием, действующим в пре-

“ Цалиев Александр Михайлович - д. ю. н., профессор, зав. кафедрой конституционного и административного права СК ГМИ (ГТУ), заслуженный юрист РФ, член Президиума совета судей РФ (kafedra-pd@skgmi-gtu.ru).

1 Нормативный правовой акт, регламентирующий правовой статус, организацию, порядок деятельности определенных государственных органов. См.: Большой юридический словарь. Под ред. А. Я. Сухарева. М.,2007. С. 495. 
делах прав, предоставленных ему Осетинским национальным собранием; б) высшей правительственной властью, осуществляющей контроль и руководство всеми органами управления и суда.

Национальный совет назначал из состава депутатов постоянно функционирующий орган в составе 10 человек, по образу президиума, который являлся органом государственного управления и решал текущие управленческие задачи.

Таким образом, Национальный совет являлся одновременно законодательным и исполнительнораспорядительным органом власти. С его помощью была предпринята попытка избежать ненужного кровопролития, а насущные вопросы жизнедеятельности народа призваны были решаться в конституционно установленных рамках.

В Конституции, в отдельном разделе, регламентировались законодательные права Национального совета: он давал толкование постановлениям Национального собрания; издавал законоположения, не противоречащие существующим постановлениям Национального собрания; пользовался правом обложения населения прогрессивно-подоходным налогом; имел право, в исключительных случаях, издавать постановления по вопросам текущего момента, каковые он обязан был вносить на очередную сессию Национального собрания. Национальный совет имел право законодательной инициативы. Все законодательные предложения, вносимые на утверждение Национального собрания отдельными лицами и различными учреждениями, предварительно рассматривались Национальным советом и только с его заключения представлялись собранию. Сказанное свидетельствует о том, что Положение наделяло Национальный совет юридическими функциями конституции.

Следующий раздел Конституции назывался «Право управления». Согласно статье 6 Осетинский национальный совет организует на территории Oceтии управление и национальные воинские силы, контролирует все существующие учреждения, хозяйственные организации и руководит их деятельностью.

В соответствии со статьей 7 Конституции комисcap, начальник народной милиции, заведующие отдельными высшими органами народного управления избираются Национальным собранием. Следующая статья предусматривала, что помощники комиссара и заведующие отдельными высшими органами народного правления предлагаются самими комиссарами и заведующими и утверждаются Национальным советом. «Комиссары участков избираются на участковых собраниях, утверждаются Национальным советом и подчиняются Комиссару округа».

Другой раздел Конституции назывался «Право представительства» и по существу выполнял внешнеполитическую функцию Конституции. Так, согласно статье 10 Осетинский национальный совет избирал представителя осетинского народа в Центральный комитет горцев. Национальный совет, говорится в статье 11 данного раздела, имеет самостоятельного представителя в Тефлисе, для защиты национальных интересов, кроме этого, согласно статье 12, Oce- тинский национальный совет имеет право заключать договоры с соседними народами, но эти договоры вносятся на окончательное утверждение очередной и чрезвычайной сессии Национального собрания.

Таким образом, договорная практика между субъектами РФ и фредеральным центром и субъектами РФ, которая возникла после разработки и принятия Федеративного договора 1992 г., региональную правовую основу получила еще в 1918 г. в Осетии. Договорная практика логична и оправдана, поскольку она позволяет учитывать исторические, экономические, природно-климатические, географические и иные особенности субъектов РФ, что необходимо для более эфффективного государственно-правового, социально-экономического и культурного развития народов. Необходимость и возможность их учета предусматривается в утвержденных указом Президента РФ В.В. Путина от 16 января 2017 г. «Основах государственной политики регионального развития Российской Федерации на период до 2025 г.».

Как правильно отмечает Л.В. Андриченко, многообразие региональных условий, различие в ресурсных потенциалах, уникальные черты исторического развития, а также специфика социокультурного ландшафрта образующих нашу страну территорий обуславливает необходимость применения диффреренцированного подхода в реализации государственной региональной политики Российской Федерации [2]. Поэтому в федеративном государстве, в его государственно-правовой политике и практике, наряду с общим, универсальным подходом в отношениях между федеральными и региональными органами государственной власти, должен быть индивидуальный подход, учитывающий специфические условия субъекта Российской Федерации. Именно этого, помимо всего прочего, добивались разработчики Федеративного договора 1992 года, о чем свидетельствую как его участник. В дальнейшем государственно-правовом развитии республик Северного Кавказа следует иметь в виду не только нынешние местные особенности, но и особенности исторического характера, обуславливающие договорную практику взаимоотношений между национально-государственными образованиями.

Из вышесказанного можно сделать вывод, что, согласно Конституции, Осетинский национальный совет, во-первых, был вполне легитимным органом государственной власти, поскольку он фрормировался Осетинским национальным собранием, выражающим волю и интересы народа; во-вторых, обладал законодательными, организационными и представительскими функциями, что позволяло ему организовать соответствующий уровень жизнедеятельности народа Осетии.

Нельзя не отметить, что в Конституции не было никаких идеологических штампов, в том числе упоминания о борьбе за установление Советской власти, об эксплуататорских классах и необходимости их ликвидации и т. п. В нем перед Осетинским национальным советом ставились совершенно конкретные социально значимые и конституционно оправданные задачи: укрепление единства и чести 
нации; ограждение неприкосновенности личности свободным правопорядком; усиление благополучия народа [3].

Убежден, что решение этих глобальных задач и по сей день остается важнейшим не только для народа Осетии. По существу они являются постоянными, неизменными составляющими Конституции любого народа. Эти извечные конституционные ценности в той или иной форме закреплены или вытекают из контекста преамбулы и соответствующих статей Конституции РФ, основных законов субъектов Российской Федерации. Так, в них основной ценностью признается человек, его права и свободы, а государство обязано признавать, соблюдать и защищать их. Согласно Федеральной Конституции и Конституции субъектов РФ политика социального государства направлена на создание условий, обеспечивающих достойную жизнь и свободное развитие человека (см. ст. 7 Конституции РФ). Данное конституционное положение подробнее раскрывается в соответствующих статьях Конституции социального характера.

Специальная глава Конституции посвящалась составу Осетинского национального совета. Национальный совет состоял из 35 депутатов, которые избирались путем двустепенных выборов согласно следующей норме: 27 депутатов от г. Владикавказа и смежных районов Северной Осетии, один депутат от осетин Моздокского уезда и один депутат от лабинских осетин ${ }^{2}$, два депутата от осетинских национальных воинских частей, один депутат от кооперативных организаций Северной Осетии и один депутат от учащихся. Кроме того, одно место предоставлялось грузинам и одно место - всем другим национальностям, живущим в Северной Осетии. Все это свидетельствует о том, что Конституция предусматривала достаточно демократический принцип формирования основного национального органа власти, где были представлены разные социальные группы и национальности.

Звание депутата Осетинского национального совета было почетно, личность депутата неприкосновенна и находилась под охраной всего осетинского народа. Депутат не мог быть лишен свобод без согласия Национального совета.

С учетом изложенного нельзя согласиться с утверждением о том, что с избранием на 1-ом областном съезде Советов, проходившем 21-29 января 1925 г. во Владикавказе и избравшим Северо-Осетинский областной комитет рабочих, крестьянских, красноармейских и казачьих депутатов, «осетинский народ впервые за всю историю создал собственное государственное управление» [4].

Как мы уже отмечали, еще 1 февраля 1918 г. был учрежден такой орган власти и управления, как Осетинский национальный совет, в который в качестве секции входил еще и Юго-Осетинский национальный совет. Секция Южной Осетии имела своего постоянного представителя в Осетинском национальном совете. По совместному решению Юго-Осетинского и Северо-Осетинского советов для решения общеосе- тинских или чрезвычайных вопросов не реже одного раза в год должна была созываться сессия Всеосетинского национального совета. К числу их чаще всего относились политические, социально-экономические и национальные вопросы.

Таким образом, можно говорить и о консолидирующей функции Конституции, что имело весьма важное значение, тем более в период, когда начали предприниматься попытки разделения осетинского народа по географическому принципу.

На основе Конституции действовали не только высшие, но и местные органы власти - национальные или народные советы, которые решали задачи местного значения. Все это свидетельствует о том, что оно осуществляло одну из важнейших фрункций Конституции - учредительную.

Анализируя и обобщая изложенное, становится вполне очевидным, что, как по содержанию вопросов, регулируемых в Положении, их социальной значимости, так и по структуре, компетенции и разновидности органов власти и решаемым ими задачам, оно, вопервых, полностью соответствует правовым характеристикам Конституции, определяющей в том числе высшие органы государства, порядок их формирования и функционирования, их полномочия и взаимные отношения; во-вторых, свидетельствует о начале фрормирования осетинской национальной государственности, характерной особенностью которой является наличие органов власти, их законное формирование и легитимность. В этом смысле Положение выполняло роль стабилизирующей функции Конституции.

Вышеуказанные функции свойственны практически любой Конституции $[5,6]$ и в этом одна из важнейших ее социальных ценностей. Тем не менее в Центре, как и в свое время обер-прокурор Святейшего синода К.П. Победоносцев, считали, что и Парламент, и Конституция одинаково губительны для России [7]. Среди некоторых партийных работников постреволюционного периода, как пишут в специальной литературе, бытовало также мнение о ненужности Конституции, как и вообще писаных законов, якобы связывающих руки пролетариату, установившему свою диктатуру [8]. Даже такой видный государственный деятель и известный юрист, как П.И. Стучка, в 1918 г. занимавший должность наркома юстиции, сомневался в необходимости разработки Конституции. Он считал, что переходный от капитализма к коммунизму период «не укладывается в твердые рамки писаного основного закона» и что диктатура пролетариата «плохо вяжется со словами «писаный закон» [8].

Сложилась парадоксальная ситуация: народ Осетии, веками решавший вопросы своей жизнедеятельности на основе норм неписаного права (адатов) и безусловного их соблюдения, в сложнейший революционный период и в условиях начавшейся гражданской войны осознал, особенно в лице своих передовых представителей, что в такое сложное время архиактуальным становится разработка и принятие писаного Основного закона. На его основе и следует

${ }^{2}$ Ныне село Коста-Хетагурово Карачаево-Черкесской автономной области. 
сформировать легитимные органы официальной власти, с помощью которых только и можно минимизировать негативные социальные последствия борьбы за государственную власть и организовать свою жизнедеятельность. В то же время представители Центра, с целью удержания и укрепления своей власти, не хотели себя и создаваемые ими органы власти строго связывать рамками писаного закона в виде Конституции. Как тут не вспомнить выдвинутый революционными идеологами 90-х г. лозунг «неконституционной Конституции» для оправдания расстрела Белого дома в 1993 г. [7].

Уверен, что только народ, знающий и соблюдающий нормы писаного и неписаного права (обычного права), в данном случае - осетинского (ирон æъдæуттæ), основанных на правилах морали и нравственности, имеет историческую перспективу, о чем свидетельствует многовековая история человечества. Если иметь в виду осетин и их далеких предков, то им удалось в своей истории высоко поднять не только честь воинской славы, но и социальное значение норм обычного права в общественной и частной жизни. Еще в конце XIX в. известный ученый В.Б. Пфраффр писал, что осетинские обычаи действуют со всей силой неизменных законов природы, не позволяющих не малейшего отступления от них и не малейшего исключения [9].

Как правильно пишет известный ученый-юрист Д.Ю. Шапсугов, нельзя не заметить некое природное пристрастие народов Северного Кавказа к правовым формам организации общественной жизни, пронизанным идеей свободы, которая составляла едва ли не главный компонент их внутреннего сознания, менталитета, особенно в многочисленных вольных обществах, представлявших собой достаточно распространенную форму жизнедеятельности этих народов. «Трагические катастрофы, многократно выпадавшие на долю этих народов и ставившие их на грань жизни и смерти, заставлявшие испытывать рабские состояния, не смогли вытравить из их сознания дух правовой свободы, которая оказалась присущей им на генетическом уровне» [10].

С учетом сказанного необходимо активизировать научные исследования не только норм писаного, но и неписаного права. На социальную значимость последних в регулировании общественных отношений в последнее время все чаще обращают внимание известные ученые [11], и это вполне логично и оправдано. Так, в традиционных обществах, каковыми, в частности, в значительной мере продолжают оставаться северокавказские республики, общественные отношения не могут в полном объеме и эффективно регулироваться нормами конституции и текущего законодательства. В этом процессе должны быть задействованы востребованные в быту нормы обычного права. Их неприятие разрывает историческую ткань между прошлым и будущим. В то же время каждое явление представляет собой единство прошлого, настоящего и будущего. Поэтому, изучая современное право, «мы должны серьезно, ответственно и бережно учитывать и использовать сохранившиеся в рос- сийской социальной ткани неписаные нормы здоровой массовой регуляции. Мы должны их использовать и поддерживать хотя бы потому, что только они по большому счету реально восполняют все еще недостаточную эффрективность законодательно-правового регулирования, отмечает председатель Конституционного суда России В.Д. Зорькин [12]. В другой своей работе он указывает, что «в любой социально-государственной системе корневую основу общественного порядка составляет в первую очередь неписаный закон, а именно это этико-нормативное поле, то есть массовые представления о должном и справедливом. Противоречивость, разорванность, неполнота этого поля превращает правовую модернизацию российского общества в очень сложную проблему» [13]. Для ее решения, как правильно пишет Д.Ю. Шапсугов, необходимо иметь в виду, что «новая эпоха не отменяет принципа органичности правового развития, носителем которого выступало право традиционного общества. Этот принцип является символом неотчуждаемости права от человека. Его игнорирование порождает массу труднорешаемых проблем для человека: неприятие и неисполнение законодательства, не учитывающего его интересы, противодействие государству, принимающему и реализующему такие законы, которое может приобретать крайне насильственные формы. В конечном итоге подобная универсализация правового регулирования ведет к катастрофическим последствиям, препятствует развитию процессов формирования духовно сильных общностей, созданию правового мира» [14]. В этом сегодняшнем мире, как и в советский период, когда все строилось, особенно институты власти, права и правосознания, на полном отрицании всего того, что было до новой власти, приходит все большее понимание исторической связи времен, эпох. Это обуславливает необходимость учета опыта прошлого, его творческого использования. Было бы недальновидно не замечать того положительного опыта прошлого, благодаря которому возникли современное государство и право. Поэтому прав профрессор Д.Ю. Шапсугов, который пишет, «что пора заняться нашим мышлением в плане более глубокого познания истории народов Северного Кавказа, выработать его реальные технологии, выяснить степень его пронизанности методологической культурой, определить исследовательские установки, подходы, парадигмы и характер их использования в исследовании реальных исторических процессов» [15]. Это более всего касается истории государства и права народов Северного Кавказа, поскольку именно эти вопросы оказались во многом вне поля зрения историков и юристов, в частности, Осетии XX века. Анализ их показывает, что они освещаются частично и никоим образом не могут претендовать на всестороннее, комплексное и глубокое исследование. Это объясняется тем, что советская историческая наука и правоведение, как правильно отмечает П.А. Кузьминов, фактически отказались изучать прошлое народов России с точки зрения влияния российского законодательства на повседневную жизнь общества [16]. Так, история Осетии советского периода практи- 
чески рассматривается и раскрывается через призму происходивших в ней политических процессов, социально-экономическое, промышленное и культурное развитие. Можно подумать, что все это происходило само по себе, без всяких усилий государственных и местных органов власти, вне рамок Конституции и основанного на ней соответствующего законодатель- ства и права конкретного региона. Конечно, это не так, поэтому долг, особенно местных специалистов, в первую очередь юристов, исследовать и раскрывать государственно-правовое развитие ${ }^{3}$ Осетии, с тем, чтобы с учетом этого материала определить наиболее важные и оптимальные пути дальнейшего формирования ее государственности и права.

\title{
ЛИТЕРАТУРА
}

1. Газета «Горская жизнь» № 38, 17 февраля 1918 г

2. Андриченко Л.В. Стратегия государственного регионального развития Российской Федерации: правовые основы // Журнал Российского права. 2017. № 5. С. 5.

3. Архив СОНИИ, фр.1., оп. 1, д. 107, л. 59.

4. История Северо-Осетинской АССР. Под ред. М.С. Тотоева. - Орджоникидзе, 1966. С. 170,171.

5. Авакьян С.А. Конституция России: природа, эволюция, современность. - М., 2000. С. 11-15.

6. Черепанов В.А. Конституционное право России. Ставрополь. 2012. С. 36-44.

7. Зорькин В.Д. Правовая трансформация России: вызовы и перспективы. В сб.: Доктрины правового государства и верховенства права в современном мире. - М., 2013. С. 33. 8. Кукушкин Ю.С., Чистяков О.И. Очерки истории Советской Конституиии. - М., 1980. С. 7.

9. Пфаффф В.Б. Народное право Осетии. - СКК, 1871. С. 169. 10. Шапсугов Д.Ю. Правовой мир как реальность и научная проблема. В сб.: «Правовой мир Кавказа: прошлое, настоящее, будущее» (Материалы международной научно-практической конфреренции). - Ростов-на-Дону. 2011. С. 7.
11. Стратегия правового развития России. / Под ред. О. Я. Рыбакова. - М., 2016.

12. Зорькин В.Д. Проблемы конституционно-правового развития России (к 20-летию Конституции РФ) // Конституционное правосудие. 2014. С. 2.

13. Зорькин В.Д. Право в условиях глобальных перемен. M., 2013. С. 52.

14. Шапсугов Д.Ю. Теоретико-правовые основания исследований правового мира Кавказа // Правовой мир Кавказа: прошлое, настоящее, будущее. Мат-лы междунар. научнопрактич. конфь., Нальчик, 14-15 апреля 2011 г. С. 12.

15. Шапсугов Д.Ю. Проблемы методологии исследования государственно-правового развития народов Кавказа. Мат-лы III междунар. научно-практич. конф., Нальчик Ростов-на-Дону. 2013.

16. Кузьминов П.А. Изучение правовых норм горских народов в советском кавказоведении // Система власти и права автохтонных народ Кавказа, Российской империи, Советов (XVIII-XX вв.): сравнительный анализ / Под ред. Д.А. Шапсугова. Мат-лы VI междунар. научно-практич. конф. Нальчик - Ростов-на-Дону. 2016. С. 78.

\section{AN IMPORTANT EVENT IN THE HISTORY OF REGIONAL CONSTITUTIONALISM (TO THE 100TH ANNIVERSARY OF THE ADOPTION OF THE 1ST CONSTITUTION OF OSSETIA)}

\section{A.M. Tsaliev}

Dr, Professor, head of the chair of constitutional and administrative law, honored lawyer of the Russian Federation, member of the Presidium of the Council of Judges of the Russian Federation(kafedra-pd@skgmi-gtu.ru).

\begin{abstract}
The article considers and analyzesthe Provision "On the Ossetian National Council" adopted on February 1, 1918, its structure and powers, the tasks of the authorities. It gives convincing arguments which testify that the mentioned Provision became the 1 st Constitution of Ossetia, it substantiates the interconnection of written and unwritten law, the social value of norms of customary law.
\end{abstract}

Keywords: 5th Congress of Ossetian people, the Provision "On the Ossetian National Council", National Assemblies, 1st Constitution of Ossetia, functions of the Constitution, written and unwritten law.

\section{REFERENCES}

1. Gazeta «Gorskaya zhizn'» № 38, 17 fevralya $1918 \mathrm{~g}$.

2. Andrichenko L.V. Strategiya gosudarstvennogo regional'nogo razvitiya Rossijskoj Federacii: pravovye osnovy // ZHurnal Rossijskogo prava. 2017. № 5. S. 5.

3. Arhiv SONII, f.1., op. 1, d. 107, I. 59.

4. Istoriya Cevero-Osetinskoj ASSR. Pod red. M.S. Totoeva. Ordzhonikidze, 1966. S. 170,171.

5. Avak'yan S.A. Konstituciya Rossii: priroda, ehvolyuciya, sovremennost'. - M., 2000. S. 11-15.

6. CHerepanov V.A. Konstitucionnoe pravo Rossii. - Stavropol' 2012. S. 36-44.

7. Zor'kin V.D. Pravovaya transformaciya Rossii: vyzovy i perspektivy. V sb.: Doktriny pravovogo gosudarstva i verhovenstva prava $v$ sovremennom mire. - M., 2013. S. 33

8. Kukushkin YU.S., CHistyakov O.I. Ocherki istorii Sovetskoj Konstitucii. - M., 1980. S. 7.

9. Pfaff V.B. Narodnoe pravo Osetii. - SKK, 1871. S. 169.

10. SHapsugov D.YU. Pravovoj mir kak real'nost' i nauchnaya problema. V sb.: "Pravovoj mir Kavkaza: proshloe, nastoyashchee, budushchee» (Materialy mezhdunarodnoj nauchno-prakticheskoj konferencii). - Rostov-na-Donu. 2011. S. 7.
11. Strategiya pravovogo razvitiya Rossii. / Pod red. O. YA. Rybakova. - M., 2016.

12. Zor'kin V.D. Problemy konstitucionno-pravovogo razvitiya Rossii (k 20-letiyu Konstitucii RF) // Konstitucionnoe pravosudie. 2014. S. 2.

13. Zor'kin V.D. Pravo v usloviyah global'nyh peremen. - M., 2013. S. 52.

14. SHapsugov D.YU. Teoretiko-pravovye osnovaniya issledovanij pravovogo mira Kavkaza // Pravovoj mir Kavkaza: proshloe, nastoyashchee, budushchee. Mat-ly mezhdunar. nauchnopraktich. konf., Nal'chik, 14-15 aprelya 2011 g. S. 12.

15. SHapsugov D.YU. Problemy metodologii issledovaniya gosudarstvenno-pravovogo razvitiya narodov Kavkaza. Mat-ly III mezhdunar. nauchno-praktich. konf., Nal'chik - Rostov-na-Donu. 2013.

16. Kuz'minov P.A. Izuchenie pravovyh norm gorskih narodov $v$ sovetskom kavkazovedenii // Sistema vlasti i prava avtohtonnyh narod Kavkaza, Rossijskoj imperii, Sovetov (XVIII-XX vv.): sravnitel'nyj analiz / Pod red. D.A. SHapsugova. Mat-ly VI mezhdunar. nauchno-praktich. konf. Nal'chik - Rostov-na-Donu. 2016. S. 78. 